\title{
Synthesis in vitro of linoleic acid by rumen liquor of calves
}

\author{
BY D. SKLAN, P. BUDOWSKI AND R. VOLCANI \\ The Volcani Institute of Agricultural Research, Bet Dagan, and \\ The Faculty of Agriculture, The Hebrew University of Jerusalem, Rehovot, Israel
}

(Received 25 October 1971 - Accepted I7 February 1972)

\begin{abstract}
I. Rumen liquor from calves $3-5$ weeks old, and a supernatant fraction prepared by centrifugation from rumen fluid of older calves showed an increase in octadecadienoic acid during aerobic incubation, but not during incubation under strictly anaerobic conditions.

2. The lipoxygenase test revealed the presence of the cis,cis-1,4-pentadiene system in the product formed on incubation, whereas oxidative degradation showed it to belong to the $\omega 6$ family. The results point to linoleic acid as the principal product formed.

3. Incubations in the presence of $\left[\mathrm{I}^{14} \mathrm{C}\right]$ oleic acid resulted in the incorporation of $4-7 \%$ of the label into the octadecadienoic acid fraction, whereas similar tests with labelled stearic acid caused about $\mathbf{I} \%$ incorporation.

4. These results, in conjunction with the observation that the increase in $18: 2$ is always accompanied by a decrease in $18: 0+18: 1$ of approximately equal magnitude, indicate that linoleate is being formed by aerobic desaturation of more saturated fatty acids.
\end{abstract}

We have previously reported (Sklan, Volcani \& Budowski, r97r) that when fluid from the immature rumen of 3 - to 5 -week-old calves was incubated, an increase in the proportion of octadecadienoic acid was observed, accompanied by a decrease in that of stearic + oleic acids, without change in the amount of total fatty acids. Samples taken from older calves fed on a milk replacer diet behaved similarly, but when the animals were accustomed to a diet of roughage and concentrate, rumen liquor appeared to lose this ability to synthesize octadecadienoic acid; instead, the usual hydrogenating activity began to appear when the animals were about 5 weeks old. However, centrifuged rumen fluid samples from older calves, and also from cows and sheep, yielded a bacteria-containing, protozoa-free supernatant fraction in which octadecadienoic acid was consistently formed on incubation.

The formation of octadecadienoic acid by rumen micro-organisms was surprising, since it represented an apparent reversal of the usual hydrogenation process. The present study was undertaken in order $(a)$ to study the effects of strictly anaerobic conditions and the addition of fat on this process, $(b)$ to characterize the octadecadienoate formed, and $(c)$ to establish the possible nature of the precursor or precursors involved.

\section{EXPERIMENTAL}

\section{Animals and sampling}

The animals used in this work were thirty-one Israeli-Friesian calves of both sexes, housed singly in cages on straw bedding. All calves received colostrum during the first $3 \mathrm{~d}$ of life and were subsequently fed once daily a commercial milk replacer (Premin Ltd, Tel-Aviv). The animals had access to solid food (hay and pelleted concentrate). Their liquid diet was progressively reduced and withdrawn by the end of 6 weeks. 
Samples of rumen contents were obtained from calves at the ages indicated by suction through a stomach-tube. Samples were obtained $20 \mathrm{~h}$ after the last milk feeding, and solid food was withheld for $\mathrm{I} h$ before sampling. All samples were strained through two layers of cheese-cloth and transferred to the laboratory for incubation. In some of the experiments supernatant fractions were prepared by centrifugation at $6500 \mathrm{~g}$ for $5 \mathrm{~min}$ at room temperature. Fractions were also prepared by further centrifugation at $74000 \mathrm{~g}$ at $4^{\circ}$ for $30 \mathrm{~min}$. In comparative experiments, portions or fractions of the same sample of rumen liquor were investigated; otherwise, measurements involved one liquor sample per calf.

\section{Incubation}

Samples of strained rumen fluid or supernatant fraction ( $1 \circ \mathrm{ml}$ ) were incubated in test-tubes $(10 \times 1.5 \mathrm{~cm})$ placed in a water-bath at $39^{\circ}$ and shaken at about 60 strokes/ min for the periods indicated (see tables and Fig. I). Where anaerobic conditions were investigated, incubation was carried out under nitrogen, after alternately applying vacuum and passing nitrogen through the sample. Previous attempts to flush the space above the liquid with carbon dioxide did not result in complete removal of oxygen from the samples (Sklan et al. 197I) and, furthermore, affected the $\mathrm{pH}$ of the solutions.

In some of the tests, various amounts of commercial milk replacer were added, as indicated later. The dry powder contained $17 \%$ fat having the following fatty acid composition (\%): shorter than $\mathrm{C}_{16}, 6.5 ; 16: 0,19.3 ; 18: 0,23.5 ; 18: 1,42 \cdot \mathrm{I}$; and I $8: 2,8 \cdot 6$.

\section{Preparation and gas-liquid chromatography $(G L C)$ of methyl esters}

Rumen liquor samples, taken before and after incubation, were saponified with ethanolic $\mathrm{KOH}$, the unsaponifiable matter was removed, and the fatty acids were freed with $\mathrm{HCl}$, extracted and methylated by refluxing for $\mathrm{I} h$ with methanol containing $3 \%(\mathrm{v} / \mathrm{v})$ sulphuric acid. The composition of the methyl esters was determined by GLC as described previously (Sklan et al. I971). The results for $18: 2$ were reproducible within $0.2 \%$ (of total fatty acids).

\section{Thin-layer chromatography (TLC) separations}

Methyl octadecadienoate was separated from the mixed methyl esters on silica gel $\mathrm{G}$ impregnated with $5 \%$ silver nitrate, according to the method of Morris ( 1964 ).

\section{Characterization and determination of linoleate}

In addition to GLC, the following procedures were used: (a) lipoxygenase (EC I.I3.I.13) assay of $c i s, c i s-1,4$-pentadiene was as described by MacGee (1959); (b) oxidative degradation and quantitative determination of the hexanoic acid formed was as follows. Mixed methyl esters were oxidized with Von Rudloff's reagent, according to the technique described by Downing \& Greene (1968), with the following modification. The step involving pyrolysis-methylation was omitted; instead, portions of the hexane solution containing the reaction products extracted from the acidified reaction mixture were submitted direct to GLC. This was done on a Packard instrument, 
fitted with a flame-ionization detector, on a column $2.4 \mathrm{~m} \times 3 \mathrm{~mm}$ packed with $\mathrm{I} 5 \%$ diethylene glycol succinate polyester on Chromosorb $W$. The column temperature was $135^{\circ}$, and nitrogen was used as the carrier gas. This produced a sharp peak of hexanoic acid. Before using the column again, the less-volatile components were removed by raising the temperature to $185^{\circ}$. The oxidation method was standardized for quantitative use by taking various amounts of methyl linoleate through the oxidation procedure and plotting the area of the hexanoic acid peak against the linoleate equivalent injected onto the column. The yield of hexanoic acid obtained from linoleate was determined with the help of a second calibration curve showing peak area plotted against amount of hexanoic acid injected.

\section{Tests with labelled precursors}

The precursors tested were $\left[{ }^{1}{ }^{14} \mathrm{C}\right] \mathrm{oleic}$ acid, specific activity $48 \mathrm{mCi} / \mathrm{mmol}$, radiopurity $99.5 \%$ and $\left[\mathrm{I}^{14} \mathrm{C}\right]$ stearic acid, specific activity $288 \mathrm{mCi} / \mathrm{mmol}$, radiopurity $99 \%$ (Applied Science Laboratories, Inc., State College, Pennsylvania). The labelled acids dissolved in hexane were placed into the test-tubes and the solvent was evaporated under nitrogen. Rumen liquor was added and the contents mixed by gentle swirling. Preliminary tests showed complete dispersion of the label in the samples. At the end of the incubation period and, in parallel samples, immediately after mixing the labelled acids with the rumen liquor, fatty acids were extracted and methylated, as described for GLC analysis, and separated by TLC on silver nitrate-impregnated silica gel $\mathrm{G}$. The methyl linoleate thus separated was eluted with chloroform and transferred to scintillation vials. The solvent was evaporated under nitrogen, and the residue was dissolved in $10 \mathrm{ml}$ of scintillation medium containing $0.5 \%$ PPO and $0.015 \%$ dimethyl POPOP in toluene. Radioactivity was measured in a Packard Tricarb liquid-scintillation counter.

\section{RESULTS}

\section{Effect of anaerobic conditions}

Our previous study (Sklan et al. 197I) had shown that octadecadienoic acid was formed when rumen liquor from young calves was incubated either in air or after replacing the atmosphere above the samples with carbon dioxide. In the present study incubations under strictly anaerobic conditions were undertaken for comparative purposes. The results (Table I) show that insignificant increases in $18: 2$ occurred under anaerobic conditions, whereas a pronounced rise in $18: 2$ occurred in samples incubated under air. Samples treated with nitrogen as for anaerobic incubation that were subsequently incubated under air, exhibited full synthesizing activity. As reported previously (Sklan et al. 1971), 18:2, was formed both by whole rumen fluid from calves $3^{-5}$ weeks old and the $6500 \mathrm{~g}$ supernatant fraction obtained from older calves.

\section{Evidence for the involvement of bacteria}

Table 2 presents the results of incubations carried out with fresh and boiled fluid, and with the fractions obtained by centrifugation. It is seen that boiled rumen liquor, 
Table I. Effect of anaerobic conditions on change in fatty acid composition of calf rumen liquor during incubation at $39^{\circ}$ for $24 \mathrm{~h}$

Mean changes

Age of calves Rumen liquor
(weeks) fraction

3-5 Wholet

$5^{-12}$ Supernatant, $6500 \mathrm{~g}$

3-5 Whole

$\begin{array}{lc}\begin{array}{c}\text { Type of } \\ \text { incubation }\end{array} & \begin{array}{c}\text { No. of } \\ \text { calves }\end{array} \\ \text { Aerobic } & 3 \\ \text { Anaerobic } & 3 \\ \text { Aerobic } & 6 \\ \text { Anaerobic } & 6 \\ \text { Aerobic } & 3 \\ \text { Anaerobic } & 3 \\ \text { Aerobict } & 3\end{array}$

in fatty acid composition $\pm \mathrm{SD}$

\begin{tabular}{|c|c|c|c|}
\hline I 6:0 & I8:0 & $18: 1$ & $18: 2$ \\
\hline $\begin{array}{l}-\mathrm{I} \cdot 8 \pm \mathrm{I} \cdot 4 \\
-0.2 \pm 0.8\end{array}$ & $\begin{array}{l}-2.4 \pm 0.6 \\
+0.7 \pm 0.4\end{array}$ & $\begin{array}{l}-5 \cdot 1 \pm x \cdot 6 \\
-I \cdot 0 \pm 0.9\end{array}$ & $\begin{array}{l}+9.3 \pm 2.3 \\
+0.6 \pm 0.9\end{array}$ \\
\hline $\begin{array}{l}+0.3 \pm 0.9 \\
+0.5 \pm 0.7\end{array}$ & $\begin{array}{l}-3.5 \pm I \cdot 4 \\
+0.2 \pm I \cdot 6\end{array}$ & $\begin{array}{l}-6 \cdot 3 \pm 2 \cdot 4 \\
-3 \cdot 0 \pm 2 \cdot I\end{array}$ & $\begin{array}{l}+9 \cdot 6 \pm 3 \cdot 1 \\
+1 \cdot 3 \pm 0.7\end{array}$ \\
\hline $\begin{array}{l}+0.8 \pm I \cdot 3 \\
+1.0 \pm 1.9 \\
-0.5 \pm I .6\end{array}$ & $\begin{array}{l}-6.3 \pm 2.1 \\
+0.8 \pm 0.6 \\
-3.8 \pm 0.7\end{array}$ & $\begin{array}{l}+0.2 \pm 3.1 \\
-0.2 \pm 2.7 \\
-1.7 \pm 3.1\end{array}$ & $\begin{array}{l}+5.4 \pm I \cdot 5 \\
-I \cdot 8 \pm I \cdot 6 \\
+4.8 \pm I \cdot 0\end{array}$ \\
\hline
\end{tabular}

* Difference between concentrations (as \% of total fatty acids) bcfore and after incubation; the + or - signs before the means indicate increase or decrease respectively.

$\dagger 0.5 \mathrm{ml}$ milk replacer added per $10 \mathrm{ml}$ sample.

‡ Samples pretreated as for anaerobic incubation but incubated aerobically.

Table 2. Formation of $18: 2$ during aerobic incubation at $39^{\circ}$ for $6 h$ of fractions obtained by centrifugation of rumen liquor from four calves $3^{-5}$ weeks old

Mean changes

Rumen liquor fraction

$\begin{array}{cc}\text { in fatty acid composition* } \pm S D \\ I 8: 0+18: 1 & 18: 2 \\ -2.1 \pm 1.6 & +3.1 \pm 1.3 \\ +0.2 \pm 0.4 & +0.1 \pm 0.3 \\ -I .9 \pm 1.1 & +3.4 \pm 1.4 \\ -0.1 \pm 0.2 & +0.1 \pm 0.3 \\ -I .8 \pm 1.0 & +2.9 \pm 0.8 \\ -1.4 \pm 0.7 & +2.7 \pm 1.1\end{array}$

Statistical analysis of the changes in $18: 2$ shows that the results fot whole, boiled rumen liquor and supernatant fraction $B$ differ significantly $\left(P<0^{\circ} \circ\right.$ I $)$ from all other results.

* Difference bctween concentrations (as \% of total fatty acids) before and after incubation; the + or - signs before the means indicate increase or decrease respectively.

+ Obtained from whole, fresh rumen liquor by centrifugation at $6500 \mathrm{~g}$ for $\mathrm{s} \mathrm{min}$.

I Obtained from supernatant $A$ by centrifugation at $74000 \mathrm{~g}$ for $30 \mathrm{~min}$ at $4^{\circ}$.

and the fluid clarified by centrifugation at $74000 \mathrm{~g}$, were completely inactive with respect to $18: 2$ formation. The $6500 \mathrm{~g}$ supernatant fraction, which contained bacteria visible under the microscope but no protozoa or food particles, was active. The pellet obtained from this supernatant fraction by high-speed centrifugation was resuspended in either boiled or clarified rumen liquor and was found to be active. Thus, the activity of the $6500 \mathrm{~g}$ supernatant fraction noted in this and previous work (Sklan et al. r97I) was associated with the particulate bacteria-containing fraction.

\section{Effect of added substrate}

Incubations were carried out either without exogenous substrate or in the presence of milk replacer supplying additional lipids in amounts up to four times the amount of endogenous fatty acids. The increase in octadecadienoic acid during incubation was plotted against the amount of fat supplied by the milk replacer (Fig. I). It is clear 


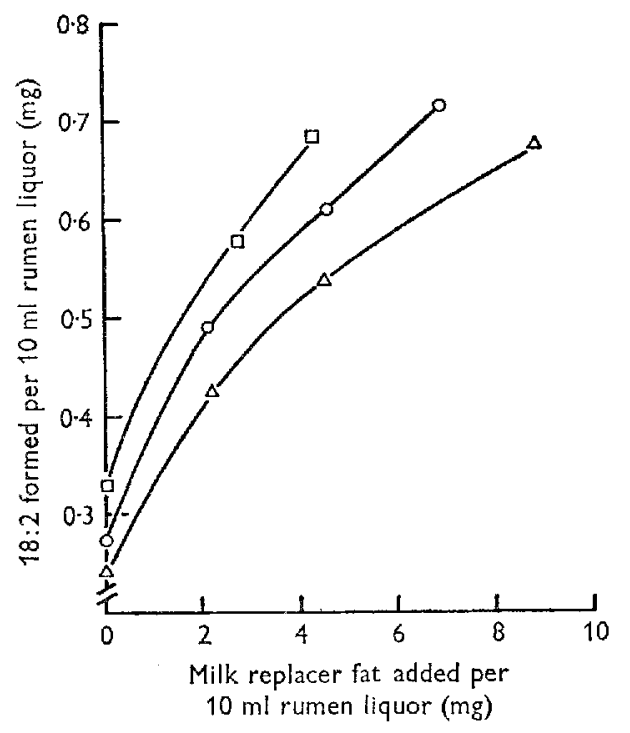

Fig. $\mathrm{x}$. Effect of addition of milk replacer on formation of $\mathrm{I} 8: 2$ upon incubation of rumen liquor. Samples were taken from cach of three calves $\left(\Pi, O, \triangle\right.$ ) $5^{-10}$ weeks old. Portions (ro ml) of the $6500 \mathrm{~g}$ supernatant fraction were incubated at $39^{\circ}$ for $24 \mathrm{~h}$ with various amounts of milk replacer. The amounts of $18: 2$ formed were computed from the fatty-acid compositions, before and after incubation, by gas-liquid chromatography with heptadecanoic acid as an internal standard.

Table 3. Formation of I8:2 by rumen liquor of calves as measured by lipoxygenase assay and gas-liquid chromatography (GLC)* (incubation time 24 h)

$\begin{array}{ccccc}\begin{array}{c}\text { Rumen liquor } \\ \text { fraction }\end{array} & \begin{array}{c}\text { Age of } \\ \text { calves } \\ \text { (weeks) }\end{array} & \begin{array}{c}\text { No. of } \\ \text { calves }\end{array} & \begin{array}{c}\text { Lipoxygenase } \\ (\%)\end{array} & \begin{array}{c}\text { GLC } \\ (\%)\end{array} \\ \begin{array}{l}\text { Whole } \\ \text { Supernatant, } 6500 \mathrm{~g}\end{array} & 3^{-5} & 7 & +2 \cdot 5 \pm \mathrm{r} \cdot 8 & +2 \cdot 6 \pm \mathrm{r} \cdot 6 \\ & 5^{-12} & 4 & +2 \cdot 9 \pm \mathrm{r} \cdot 7 & +3.3 \pm \mathrm{r} \cdot 8\end{array}$

* $0.5 \mathrm{ml}$ milk replacer added per Io $\mathrm{ml}$ rumen liquor.

+ Difference between concentrations (as \% of total fatty acids) after and before incubation.

that the extent of synthesis of octadecadienoic acid during incubation increased in proportion to the amount of substrate fat provided by the milk replacer, although the rate of increase declined at higher substrate concentrations.

\section{Characterization of the octadecadienoic acid formed upon incubation}

Lipoxygenase assay. Samples of rumen liquor were examined by the lipoxygenase assay before and after a $6 \mathrm{~h}$ incubation period. In all instances, the solutions of the isolated fatty acids exhibited absorption maxima around $234 \mathrm{~nm}$ upon treatment with lipoxygenase, but this maximum increased appreciably as a result of incubation. Table 3 shows a comparison of the increase of linoleic acid calculated from the results of the lipoxygenase assay and of GLC. It is seen that the values obtained by the lipoxygenase assay were similar to, though slightly lower than, the GLC results. Thus 


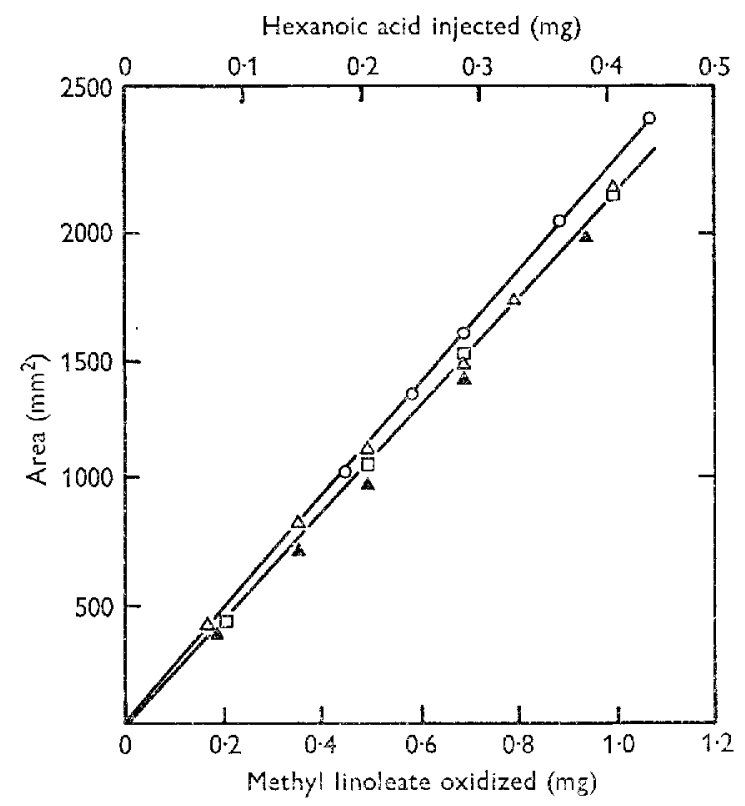

Fig. 2. Calibration of gas-liquid chromatographic method, showing hexanoic acid peak area as a function of the amount of hexanoic acid injected or methyl linoleate oxidized. $O$, hexanoic acid; $\square$, methyl linoleate; $\Delta$, different amounts of methyl linoleate made up to I $\mathrm{mg}$ with a mixture of saturated methyl esters containing $81 \%$ I $8: 0$ and $19 \% \mathrm{I} 6: 0 ; \boldsymbol{\Delta}$, different amounts of methyl linoleate made up to $\mathrm{I}$ mg with methyl oleate. The scale of hexanoic acid injected has been adjusted to correspond to the theoretical amounts formed from linoleic acid by oxidative degradation.

the increase in octadecadienoic acid was associated with a rise in the $c i s, c i s-\mathrm{I}, 4$-pentadiene system.

Oxidative degradation. Fig. 2 shows the calibration curves obtained. The area response of the hexanoic acid peak was linear when plotted as a function of either the amount of hexanoic acid injected or that of linoleate oxidized. The latter curve was not affected by the presence of saturated esters, whereas methyl oleate only slightly interfered with the response. The yield of hexanoic acid obtained by oxidizing methyl linoleate under the various conditions described in Fig. 2 was in the region of $90 \%$.

The calibration curve obtained with various amounts of methyl linoleate was used for the calculation of $\omega 6$ unsaturated fatty acids. The results of such a calculation for rumen liquor samples before and after $24 \mathrm{~h}$ incubation are presented in Table 4, together with GLC results obtained for the same samples. It is seen that incubation caused a rise in $\omega 6$ unsaturated fatty acids which paralleled the change found by GLC, though the latter appeared to be somewhat greater. Similar results were obtained when the diene fraction was separated from other methyl esters on silver nitrateimpregnated silica gel $\mathrm{G}$, before being submitted to oxidative degradation.

\section{Incubation with $\left[{ }^{1-14} \mathrm{C}\right]$ oleic and $\left[\mathrm{I}^{14} \mathrm{C}\right]$ stearic acids}

Results obtained upon incubating rumen liquor samples in the presence of $\left[\mathrm{I}^{14} \mathrm{C}\right]-$ oleic and $\left[\mathrm{I}^{14} \mathrm{C}\right] \mathrm{stearic}$ acids are presented in Table 5 . A small amount of radioactivity 
Table 4 . Formation of $18: 2$ w6 by calf rumen liquor, as determined by oxidative degradation and gas-liquid chromatography (GLC) (incubation time $24 h$ )

(Each line of results is from a different calf)

Linoleic acid by:

\begin{tabular}{|c|c|c|c|c|c|}
\hline \multirow[b]{2}{*}{$\begin{array}{l}\text { Rumen liquor } \\
\text { fraction }\end{array}$} & \multirow[b]{2}{*}{$\begin{array}{l}\text { Age of } \\
\text { calves } \\
\text { (weeks) }\end{array}$} & \multicolumn{2}{|c|}{ Oxidative degradation } & \multicolumn{2}{|c|}{ GLC } \\
\hline & & $\begin{array}{c}\text { Before } \\
\text { incubation } \\
(\%)\end{array}$ & $\begin{array}{c}\text { After } \\
\text { incubation } \\
(\%)\end{array}$ & $\begin{array}{c}\text { Before } \\
\text { incubation } \\
(\%)\end{array}$ & $\begin{array}{c}\text { After } \\
\text { incubation } \\
(\%)\end{array}$ \\
\hline & \multicolumn{5}{|c|}{ Mixed methyl esters } \\
\hline \multirow[t]{3}{*}{ Whole $\uparrow$} & $3-5$ & $6 \cdot 3$ & $20 \cdot 3$ & 7.0 & $26 \cdot I$ \\
\hline & $3-5$ & $8 \cdot 0$ & $I 7^{\cdot I}$ & 94 & $23 \cdot 3$ \\
\hline & $3-5$ & $7 \cdot 1$ & $17 \cdot 7$ & $8 \cdot 3$ & $21 \cdot 6$ \\
\hline \multirow[t]{4}{*}{ Supernatant $\dagger, 6500 \mathrm{~g}$} & $5-10$ & $6 \cdot 6$ & $17 \cdot 2$ & $7 \cdot 2$ & $2 I \cdot 5$ \\
\hline & $5-10$ & $7 \cdot 2$ & I 5.5 & $8 \cdot 5$ & $19 \cdot 3$ \\
\hline & $5-10$ & $I I \cdot 2$ & $18 \cdot 1$ & $13 \cdot 5$ & $23 \cdot 5$ \\
\hline & \multicolumn{5}{|c|}{ Diene methyl esters $f$} \\
\hline \multirow[t]{3}{*}{ Supernatant, $6500 \mathrm{~g}$} & $5^{-10}$ & $I \cdot 9$ & $8 \cdot 5$ & $2 \cdot 8$ & I 3.8 \\
\hline & $5^{-10}$ & $3 \cdot I$ & $7 \cdot 4$ & $3 \cdot 8$ & $10 \cdot 3$ \\
\hline & $5-10$ & $3 \cdot 3$ & $12 \cdot 2$ & $4 \cdot 1$ & $16 \cdot 9$ \\
\hline
\end{tabular}

Table 5. Incubation experiments with labelled fatty acid precursors*

\begin{tabular}{|c|c|c|c|c|}
\hline \multirow{2}{*}{$\begin{array}{l}\text { Rise in count } \\
\text { of } x: 2 \nmid \text { on } \\
\text { incubation } \\
\text { (counts } / \mathrm{min} \text { ) }\end{array}$} & \multirow{2}{*}{$\begin{array}{c}\text { Incorporation of } \\
{ }^{11} \mathrm{C} \text { into } 18: 2 \\
(\%)\end{array}$} & \multicolumn{3}{|c|}{ Change $\ddagger$, on incubation, in: } \\
\hline & & $\begin{array}{l}\text { I8:0 } \\
(\%)\end{array}$ & $\begin{array}{l}\mathrm{I} 8: \mathrm{I} \\
(\%)\end{array}$ & $\begin{array}{l}18: 2 \\
(\%)\end{array}$ \\
\hline \multicolumn{5}{|c|}{$\left[\mathrm{I}^{-19} \mathrm{C}\right]$ oleic acid $(0.025 \mu \mathrm{Ci})$} \\
\hline 2930 & $6 \cdot 6$ & $-I_{3} \cdot I$ & -0.9 & $+I I \cdot O$ \\
\hline I 599 & 3.8 & $-18 \cdot 4$ & $+10 \cdot 3$ & $+6 \cdot 5$ \\
\hline 2939 & 6.7 & $-18 \cdot 2$ & $+5 \cdot 0$ & $+\mathrm{I} 2 \cdot 8$ \\
\hline 1888 & $4 \cdot 4$ & $-8 \cdot 2$ & $-3 \cdot I$ & $+8 \cdot 3$ \\
\hline \multicolumn{5}{|c|}{$\left[\mathrm{I}-{ }^{14} \mathrm{C}\right]$ stearic acid $(0.2 \mu \mathrm{Ci})$} \\
\hline I 979 & $I \cdot 07$ & $-4 \cdot 0$ & -0.8 & +9.9 \\
\hline 1275 & 0.69 & $-3 \cdot 6$ & $-6 \cdot 6$ & $+11-2$ \\
\hline I 779 & 0.96 & $-6 \cdot 8$ & $-2 \cdot 0$ & $+8 \cdot 0$ \\
\hline 1245 & 0.67 & $-4 \cdot 0$ & $-4 \cdot 6$ & +9.8 \\
\hline
\end{tabular}

* $6500 \mathrm{~g}$ supernatant fraction from Io $\mathrm{ml}$ rumen liquor samples obtained from 5-Io weeks old calves incubated for $24 \mathrm{~h}$. Fatty-acid composition determined by gas-liquid chromatography. Each line of results is from a different calf.

$\dagger$ Dienoic methyl ester fraction scparated by thin-layer chromatography on $\mathrm{AgNO}_{3}$-silica gel G. The radioactivity of this fraction before incubation was close to 800 counts $/ \mathrm{min}$ in tests with [ $\left.\mathrm{I}-{ }^{14} \mathrm{C}\right]-$ oleic acid, and 600 counts $/ \mathrm{min}$ in tests with $\left[\mathrm{I}^{14} \mathrm{C}\right]$ stearic acid.

$\ddagger$ Calculated as explained in footnote*, Table $\mathrm{I}$.

was consistently found in the diene fraction, when the latter was separated and counted before incubation, due possibly to radioactive impurities in the labelled substrates. However, the radioactive count of this fraction increased three- to five-fold upon incubation, indicating incorporation of ${ }^{14} \mathrm{C}$ into the linoleate fraction. About $4-7 \%$ of 
$\left[{ }^{1}-{ }^{14} \mathrm{C}\right]$ oleic acid and $0 \cdot 7^{-I} \cdot \mathrm{I} \%$ of $\left[\mathrm{I}^{14} \mathrm{C}\right]$ stearic acid label appeared in the $18: 2$ fraction. The changes in fatty acid composition shown by GLC are also presented in Table 5. There was the expected increase in $18: 2$, accompanied in most of the samples by an approximately equal decrease in the sum $18: 0+18: 1$. Oleic acid by itself, exhibited changes that were highly variable and not always in the same direction.

\section{DISCUSSION}

The present work confirms and extends our earlier observations regarding the synthesis of octadecadienoic acid upon incubating rumen liquor from calves under appropriate conditions.

The comparative experiments on the effect of aerobic and anaerobic conditions show that oxygen is required for the formation of $18: 2$, and that this activity of rumen liquor is inhibited but not destroyed by the absence of oxygen. Removal of oxygen from the samples required alternate application of vacuum and bubbling of nitrogen, whereas replacing the atmosphere above the samples with carbon dioxide had earlier (Sklan $e t a l .197 \mathrm{I}$ ) proved ineffective.

The possibility that the synthesis of $18: 2$ might be caused by extraneous contamination must be discounted, since neither boiled nor clarified fresh rumen liquor displayed any activity. On the other hand, there is some evidence pointing to rumen bacteria as being involved in the synthesis of $18: 2$. Additional work is in progress to obtain more direct evidence of the participation of rumen bacteria in the synthesis of $18: 2$.

The second part of this study was concerned with the question of the nature of the octadecadienoic acid formed.

Analysis by GLC does not usually permit satisfactory distinction between isomers of methyl linoleate (Holman \& Rahm, I966), although certain separations have been achieved under conditions of high resolution.

The lipoxygenase assay is specific for the $c i s, c i s-\mathrm{I}, 4$-pentadiene system, which is characteristic of essential fatty acids. Here, this assay yielded results which paralleled those found by GLC; however, it left undefined the position of the $\omega$-double bond. A modified permanganate-periodate oxidation technique permitted the determination of the hexanoic acid produced from $\omega 6$ unsaturated fatty acid esters. Again, the results expressed as linoleic acid by means of a calibration curve (Fig. 2), indicated an increase on incubation, in agreement with the results obtained by GLC for $18: 2$.

The results obtained by GLC, lipoxygenase assay and chemical oxidation, considered together, provide strong evidence for the synthesis of $c i s$, cis-9, $\mathrm{i}$-octadecadienoic acid upon incubation. The fact that the increases shown by GLC were slightly larger than those found by the other techniques may indicate that small amounts of isomers were formed together with linoleic acid.

Precursor experiments (Table 5) indicated that desaturation of oleate is a pathway, possibly the main one, by which linoleate might be synthesized. Stearic acid too might be a precursor of linoleate although the yield of isotope incorporation was much lower. This was probably due to the existence of two successive desaturation steps, with a monoene being formed as an intermediate. Compositional changes point to such a 
mechanism: although the proportions of stearate always decreased and linoleate increased, the change in $18: \mathrm{I}$ was not consistent, owing perhaps to variations in the relative rates of the two desaturation steps. Further elucidation of the mechanism of desaturation requires separation and counting of individual fatty acids, as well as determination of specific radioactivities and proof that the label in $18: 2$ is on C-r.

Our observation that strictly anacrobic conditions inhibit the synthesis of linoleic acid seems to support the concept of desaturation. Formation of linoleate by aerobic desaturation of oleate has been reported in yeasts (Bloch, Baronowsky, Goldfine, Lennarz, Light, Norris \& Sheuerbrandt, 196r), green algae (Harris, Harris \& James, 1965) and protozoa (Korn, Greenblatt \& Lees, 1965 ). Although synthesis of $18: 2$ has been reported for Pseudomonas aeruginosa (Romero \& Brenner, 1966), the desaturation pathway from oleic acid does not appear to have been described in bacteria. Williams, Gutierrez \& Davis ( 1963 ) have presented results from which it may be inferred that mixed rumen bacteria convert some $\left[\mathrm{I}^{1}{ }^{14} \mathrm{C}\right]$ oleic acid to labelled linoleic acid. Fulco $(1969,1970)$, in his work on bacilli, has reported aerobic desaturation of $16: 0$ to $16: 2$ via an intermediate monoene. The diene formed was cis,cis-7, ro-hexadienoic acid, which has been shown to be a precursor of linoleic acid in the rat (Sprecher, 1968). According to a report by Viviani \& Lenaz (1963), linoleic acid (as determined by GLC) was synthesized in the rumen of a sheep given a fat-free diet.

The question might be raised whether the desaturation reaction represents an abnormal metabolic process, caused by an insufficient supply of nutrients to the microorganisms in vitro. The results of incubation tests carried out in the presence of increasing amounts of added milk replacer (Fig. I) show, on the contrary, that formation of $18: 2$ did not decrease, but in fact increased with a more abundant supply of nutrients. We have also carried out tests (unpublished) in the presence of added starch and have found no decrease in $\mathrm{I} 8: 2$ synthesizing activity. The effect of added milk replacer on synthesis of $18: 2$, shown in Fig. $I$, might be explained by the increasing amounts of oleic acid acting as a substrate for the desaturation reaction.

Although formation of linoleate from more saturated fatty acid precursors by rumen liquor of young calves occurs in vitro, as shown by the present results, such a process has yet to be demonstrated in vivo. Bryant, Small, Bouma \& Robinson (1958) reported that counts of aerobic bacteria were highest in the rumen of calves during the early weeks of life, and Lengemann \& Allen (1959) found a rapid fall in the number of aerobes whenever calves were transferred from liquid to solid food. The prevalence of aerobic bacterial counts in the immature rumen of the calf on a liquid diet is consistent with the hypothesis that a favourable environment exists for the microbial synthesis of linoleate.

We acknowledge the skilled technical assistance by Ofra Kedar. 


\section{REFERENCES}

Bloch, K., Baronowsky, P., Goldfine, H., Lennarz, W. J., Light, R., Norris, A. 'T' \& Sheuerbrandt, G. (1961). Fedn Proc. Fedn Am. Socs exp. Biol. 20, 92 1.

Bryant, M. P., Small, N., Bouma, C. \& Robinson, I. (1958). F. Dairy Sci. 4I, 1747.

Downing, D. T. \& Greene, R. S. (1968). Lipids 3, 96 .

Fulco, A. J. (1969). F. biol. Chem. 244, 889.

Fulco, A. J. (1970). F. biol. Chem. 245, 2985.

Harris, R. V., Harris, P. \& James, A. T. (1965). Biochim. biophys. Acta ro6, 465.

Holman, R. T. \& Rahm, J. J. (1966), Prog. Chem. Fats 9, 56.

Korn, E. D., Greenblatt, C. L. \& Lees, A. M. (1965). \%. Lipid Res. 6, 43.

Lengemann, F. W. \& Allen, N. N. (I959). J. Dairy Sci. 42, I I7 I.

MacGee, J. (1959). Analyt. Chem. 31, 298.

Morris, L. J. (1964). In New Biochemical Separations, p. 296 [A. T. James and L. J. Morris, editors]. London: D. Van Nostrand Co., Ltd.

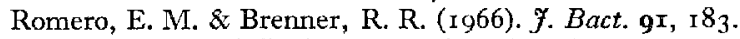

Sklan, D., Volcani, R. \& Budowski, P. (1971). F. Dairy Sci. 54, 5 I 5.

Sprecher, H. (1968). Lipids 3, 14.

Williams, P. P., Gutierrez, J. \& Davis, R. E. (1963). Appl. Microbiol. r r, 260.

Viviani, R. \& Lenaz, G. (1963). Boll. Soc. ital. Biol. sper. 39, 1836. [Chem. Abstr. (1964). 61, 16538.] 